\title{
Psychiatric Diagnosis and Clinical Trial Completion Rates: Analysis of the FDA SBA Reports
}

\author{
Arif Khan ${ }^{*, 1,2}$, Kelly Schwartz', Nick Redding', Russell L Kolts ${ }^{3}$ and Walter A Brown ${ }^{4,5}$ \\ 'Northwest Clinical Research Center, Bellevue, WA, USA; '2Department of Psychiatry and Behavioral Sciences, Duke University Medical Center, \\ Durham, NC, USA; ${ }^{3}$ Department of Psychology, Eastern Washington University, Cheney, WA, USA; ${ }^{4}$ Department of Psychiatry, Brown Medical \\ School, Providence, RI, USA; ${ }^{5}$ Department of Psychiatry, Tufts University School of Medicine, Boston, MA, USA
}

\begin{abstract}
Completion rates may affect the safety and efficacy evaluations of psychotropics. We assessed completion rates in clinical trials evaluating psychotropics for five psychiatric disorders. We also examined differences in completion rates between psychotropics and placebo in each diagnostic category. We reviewed clinical data in the Food and Drug Administration summary basis of approval reports for 20 psychotropics evaluated for the treatment of depression, schizophrenia, obsessive compulsive disorder (OCD), generalized anxiety disorder (GAD), or panic disorder, consisting of 19710 patients. Patients with OCD had the highest completion rates (78.0\%), followed by patients with panic disorder (74.4\%), GAD (69.2\%), depression (64.7\%) and schizophrenia (49.0\%). Patients assigned to placebo had significantly lower completion rates in antipsychotic clinical trials. Patients assigned to psychotropics in OCD trials had significantly lower completion rates compared to the placebo group. A greater number of early terminations relating to a lack of efficacy was seen among patients assigned to placebo (17.4\%) compared with patients assigned to psychotropics (12.2\%). A greater number of early terminations relating to adverse events was seen among patients assigned to psychotropics (10.4\%) compared with patients assigned to placebo (4.8\%). Our findings suggest that psychiatric diagnosis and treatment assignment (placebo vs psychotropic) were associated with completion rates in clinical trials. These findings may help in the design of future psychopharmacology clinical trials. Neuropsychopharmacology (2007) 32, 2422-2430; doi: I 0. I038/sj.npp. I 30136I; published online 2 I February 2007
\end{abstract}

Keywords: clinical trials; completion rates; psychiatric diagnosis; psychopharmacology; psychotropics; placebo

\section{INTRODUCTION}

Clinical trial completion rates affect safety and efficacy assessments (Mullins et al, 2005; Anderson and Tomenson, 1995; Baekeland and Lundwall, 1975; Pelagotti et al, 2004; Labelle et al, 1999). When patients terminate before the end of a trial or are lost for evaluations during a clinical trial, the result may be an inaccurate estimation of adverse effects or efficacy.

Thus, it is assumed that higher clinical trial completion rates lead to a more favorable outcome for psychotropics. Additionally, low completion rates may lead to results that have limited generalizability to larger samples of patients with the disorder (Kemmler et al, 2005). For example, results from an antidepressant clinical trial with an $85 \%$ completion rate may be considered more valid for all depressed patients compared with an antidepressant trial with only a $60 \%$ completion rate.

*Correspondence: Dr A Khan, Northwest Clinical Research Center, 1900 | |6th Ave NE, Bellevue, WA 98004, USA, Tel: + I 425453 0404; Fax: + 425453 1033; E-mail: akhan@nwcrc.net Received 23 August 2006; revised 7 January 2007; accepted 10 January 2007
A review of the literature indicates that the completion rate among antipsychotic clinical trials is roughly $47 \%$ (Arvanitis and Miller, 1997; Chouinard et al, 1993; Hamilton et al, 1998; Kane et al, 2002; Meltzer et al, 2004; Potkin et al, 2003), $54.5 \%$ for obsessive compulsive disorder (OCD) trials (Greist et al, 1995; Koran et al, 2002; Montgomery et al, 1993), 59.1\% for antidepressant trials (Claghorn et al, 1992; Cohn and Wilcox, 1985; Dunbar et al, 1991; Dunbar et al, 1993; Fabre et al, 1995; Feighner and Boyer, 1989; Fontaine et al, 1994; Lineberry et al, 1990; Lydiard et al, 1997; Mendels et al, 1995; Reimherr et al, 1990; Kiev, 1992; Rickels et al, 1992; Shrivastava et al, 1992; Smith and Glaudin, $1992), 62.1 \%$ for generalized anxiety disorder (GAD) trials (Enkelmann, 1991; Gelenberg et al, 2000; Liebowitz et al, 2002; Rickels et al, 2000; Stein et al, 1998), and 64.7\% in panic disorder trials (Andersch et al, 1991; Ballenger et al, 1998; Lecrubier et al, 1997; Lecrubier and Judge, 1997; Londborg et al, 1998; Pollack et al, 1998; Rapaport et al, 2001). These published reports represent a heterogeneous sample that is nonetheless composed exclusively of published data; publication bias is therefore a concern when considering these results.

Recently, a large federally funded clinical trial (CATIE, Lieberman et al, 2005) assessing the efficacy of five 
antipsychotic agents was published using completion rates as the primary outcome variable. Besides using this novel primary dependent variable, these researchers chose not to focus on other efficacy measures such as the Brief Psychiatric Rating Scale or the Positive and Negative Syndrome Scale. These investigators did not include a placebo control group, making the study similar to a noninferiority design rather than a superiority design.

This study failed to detect any significant differences among the five antipsychotics evaluated. Such a finding is not surprising. Trials using a design such as non-inferiority are prone to type II errors, because it is extremely difficult to power the trials to find significant differences (Leon, 2000). Furthermore, caution is warranted because the investigators could not evaluate completion rates in a placebo group using their design. This is of importance because efficacy measures and completion rates may or may not be closely related. Even more important, patients may terminate prematurely from psychopharmacology trials for different reasons when assigned to psychotropics and placebo.

Because of the ambiguous results of the CATIE trial and general lack of specificity of completion rates based on a current literature review, we assessed the underlying assumptions of completion rates as an outcome measure. Specifically, we assessed whether clinical trial design factors (Khan et al, 2004, 2005; Khan and Schwartz, 2005) such as psychiatric diagnosis, assignment to psychotropics $v s$ placebo, duration of the clinical trial, dosing schedules, and number of treatment arms are associated with psychotropic clinical trial completion rates. We noted previously that placebo response and drug-placebo differences were significantly associated with psychiatric diagnosis (Khan et al, 2005). Hence, we suspect that completion rates may also be related to psychiatric diagnosis.

We hypothesized that both patient characteristics (psychiatric diagnosis) and clinical trial features (treatment assignment, duration of the clinical trial, dosing schedule, and number of treatment arms) may be related to completion rates. This hypothesis is based on previous observations that have linked these variables with wellaccepted measures of clinical trial outcomes (Khan et al, 2003a, b, 2004, 2005).

\section{METHODS}

The US Food and Drug Administration (FDA) staff generates Summary Basis of Approval (SBA) reports on every new drug and indication for each New Drug Application (NDA). The FDA staff including physicians, chemists, pharmacologists, toxicologists, and clinical pharmacists review different aspects of the NDA and compile the data into a SBA report containing pre-clinical and clinical data reviews (in abbreviated form) on patients voluntarily participating in the respective clinical trials. The senior physician signs off on the completed report and then incorporates portions of the information into product labeling. This information is sent to the Department of Freedom of Information for public availability.

Sections of the SBA reports commonly include recommendations for approvability, an overview of the clinical program, efficacy data, safety findings, dosing recommendations, and information for use in special populations. The efficacy section details pivotal trials used to evaluate the superiority of the investigational medication over placebo or an established comparator. This section contains information such as the number of patients participating in the trials and the number of patients who complete the clinical trial. The safety section does not contain completion rates for the clinical trials, although sections may report on patient drop-outs based on the evaluated cause. However, these data do not match the data reported in the efficacy section, severely limiting their usefulness.

We obtained FDA SBA reports for each NDA of clinical trial data for the following psychotropics approved in the United States between 1985 and 2004: antidepressants: bupropion SR, citalopram, duloxetine, escitalopram, fluoxetine, mirtazapine, nefazodone, paroxetine, sertraline, venlafaxine, venlafaxine ER; antipsychotics: aripiprazole, olanzapine, quetiapine, risperidone, ziprasidone; panic agents: clonazepam, paroxetine, sertraline; OCD agents: clomipramine, fluoxetine, fluvoxamine, paroxetine, sertraline; GAD agents: buspirone, venlafaxine.

We recorded the completion rates for the 19710 patients participating in FDA phase II and phase III clinical trials evaluating psychotropic medications for five psychiatric disorders - depression, schizophrenia, anxiety, panic disorder, OCD, and GAD. In Table 1, we list all trials evaluated for each psychotropic and specify the diagnosis studied for all psychotropics that have multiple indications. The trial number, length of trial, dosing schedule (fixed vs flexible dosing), number of treatment arms, number of patients randomized to either placebo or an active medication (investigational medication or active comparator), and the number of patients who completed are listed for each study.

In Table 2, we present the percentage of completers for all patients assigned to either placebo or active medication in each diagnostic category. We rank-ordered (lowest to highest) the diagnostic categories based on the percentage of completers.

Using $\chi^{2}$ analysis, we conducted several tests. First, we determined whether significant differences in completion rates existed between participants in antidepressant, antipsychotic, anti-anxiety, panic disorder, OCD, and GAD clinical trials. For this first analysis, we assessed completion rates regardless of treatment assignment (psychotropic vs placebo). To determine whether treatment assignment influenced completion rates, we examined whether completion rates differed for patients assigned to an active medication across the psychiatric disorders.

Next, we analyzed differences among patients assigned to the placebo arm in the various clinical trials. We then evaluated whether completion rates in the psychotropic group differed significantly from the placebo group in each diagnostic category. Additionally, we evaluated whether trends existed in completion rates based on the number of treatment arms, dosing schedule (fixed $v s$ flexible), and length of trial in weeks.

In Table 3, we present the number of patients discontinuing for lack of efficacy, adverse events, and other reasons for both the psychotropic and the placebo groups in each of the five psychiatric diagnosis categories. Using $\chi^{2}$ analysis, we compared psychotropic and placebo for each of the 
Table I Demographic Information for All Studies Obtained in the FDA SBA Reports

\begin{tabular}{|c|c|c|c|c|c|c|c|c|c|}
\hline \multirow[b]{2}{*}{ Psychotropic } & \multirow[b]{2}{*}{ Trial no. } & \multirow[b]{2}{*}{ Disorder } & \multirow[b]{2}{*}{ Length } & \multirow[b]{2}{*}{ Dosing } & \multirow[b]{2}{*}{ Arms } & \multicolumn{2}{|c|}{ Placebo } & \multicolumn{2}{|c|}{ Pscyhotropics } \\
\hline & & & & & & $\mathbf{N}$ & Completers & $N$ & Completers \\
\hline & 94202 & Schizophrenia & 4 & Fix & 5 & 64 & 29 & 243 & 147 \\
\hline & 97201 & Schizophrenia & 4 & Fix & 4 & 106 & 58 & 308 & 190 \\
\hline \multirow[t]{3}{*}{ Bupropion } & 203 & Depression & 8 & Fix & 2 & 121 & 61 & 120 & 67 \\
\hline & 205 & Depression & 8 & Fix & 3 & 124 & 85 & 239 & 145 \\
\hline & 212 & Depression & 8 & Fix & 2 & 154 & 106 & 150 & 103 \\
\hline & 995 & GAD & 4 & Flex & 3 & 56 & 41 & 107 & 78 \\
\hline & 994 & GAD & 4 & Flex & 3 & 67 & 33 & 136 & 90 \\
\hline & 996 & GAD & 4 & Flex & 3 & 29 & 18 & 61 & 35 \\
\hline \multirow[t]{4}{*}{ Citalopram } & $85 \mathrm{~A}$ & Depression & 4 & Flex & 2 & 91 & 51 & 89 & 48 \\
\hline & $86|4|$ & Depression & 6 & Flex & 2 & 51 & 38 & 98 & 64 \\
\hline & 89303 & Depression & 6 & Fix & 3 & 66 & 46 & 134 & 100 \\
\hline & 91206 & Depression & 6 & Fix & 4 & 129 & 88 & 390 & 262 \\
\hline Clomipramine & 59 & OCD & 10 & Flex & 2 & 121 & 108 & 118 & 102 \\
\hline & HMAQb & Depression & 8 & Flex & 3 & 75 & 44 & 119 & 80 \\
\hline & HMATa & Depression & 8 & Fix & 4 & 90 & 62 & 264 & 181 \\
\hline & HMATb & Depression & 8 & Fix & 4 & 89 & 52 & 264 & 157 \\
\hline & $\mathrm{HMBHa}$ & Depression & 8 & Fix & 2 & 122 & 86 & 123 & 80 \\
\hline & $\mathrm{HMBHb}$ & Depression & 8 & Fix & 2 & 139 & 90 & 128 & 78 \\
\hline \multirow[t]{4}{*}{ Escitalopram } & 99001 & Depression & 8 & Fix & 2 & 189 & 160 & 191 & 160 \\
\hline & 99003 & Depression & 8 & Flex & 3 & 164 & 139 & 317 & 298 \\
\hline & MD-0I & Depression & 8 & Fix & 3 & 122 & 91 & 244 & 188 \\
\hline & MD-02 & Depression & 8 & Flex & 3 & 127 & 105 & 248 & 195 \\
\hline \multirow[t]{6}{*}{ Fluoxetine } & E079 & OCD & 8 & Fix & 4 & 57 & 42 & 160 & 119 \\
\hline & HCEP I & OCD & 13 & Fix & 4 & 89 & 76 & 266 & 205 \\
\hline & 19 & Depression & 5 & Flex & 2 & 25 & 14 & 22 & 11 \\
\hline & 25 & Depression & 5 & Flex & 2 & 24 & 14 & 18 & 10 \\
\hline & 27 & Depression & 6 & Flex & 3 & 59 & 22 & 61 & 31 \\
\hline & 62 & Depression & 6 & Fix & 3 & 104 & 64 & 415 & 256 \\
\hline \multirow[t]{2}{*}{ Fluvoxamine } & 5529 & OCD & 10 & Flex & 2 & 80 & 76 & 80 & 64 \\
\hline & 5534 & OCD & 10 & Flex & 2 & 80 & 64 & 80 & 59 \\
\hline
\end{tabular}


Table I Continued

\begin{tabular}{|c|c|c|c|c|c|c|c|c|c|}
\hline \multirow[b]{2}{*}{ Psychotropic } & \multirow[b]{2}{*}{ Trial no. } & \multirow[b]{2}{*}{ Disorder } & \multirow[b]{2}{*}{ Length } & \multirow[b]{2}{*}{ Dosing } & \multirow[b]{2}{*}{ Arms } & \multicolumn{2}{|c|}{ Placebo } & \multicolumn{2}{|c|}{ Pscyhotropics } \\
\hline & & & & & & $\mathbf{N}$ & Completers & $\mathbf{N}$ & Completers \\
\hline \multirow[t]{7}{*}{ Mirtazapine } & 003-002 & Depression & 6 & Flex & 2 & 44 & 19 & 44 & 26 \\
\hline & 003-003 & Depression & 6 & Flex & 2 & 45 & 24 & 45 & 27 \\
\hline & $003-021 / 3220$ & Depression & 6 & Flex & 3 & 48 & 21 & 93 & 49 \\
\hline & $003-022 / 3220$ & Depression & 6 & Flex & 3 & 50 & 36 & 99 & 77 \\
\hline & $003-023 / 3220$ & Depression & 6 & Flex & 3 & 39 & 34 & 97 & 69 \\
\hline & $003-024 / 3220$ & Depression & 6 & Flex & 3 & 48 & 27 & 99 & 65 \\
\hline & 84023 & Depression & 6 & Flex & 2 & 54 & 30 & 59 & 37 \\
\hline \multirow{3}{*}{ Nefazadone } & CNI04-002 & Depression & 6 & Flex & 3 & 57 & 38 & 112 & 98 \\
\hline & CNI04-005 & Depression & 8 & Flex & 3 & 91 & 61 & 169 & 112 \\
\hline & CNI04-006 & Depression & 8 & Flex & 3 & 78 & 50 & 159 & 87 \\
\hline \multirow[t]{2}{*}{ Olanzapine } & HGAD & Schizophrenia & 6 & Fix & 5 & 68 & 25 & 267 & 125 \\
\hline & HGAP & Schizophrenia & 6 & Fix & 3 & 50 & 10 & 102 & 31 \\
\hline \multirow[t]{12}{*}{ Paroxetine } & 108 & Panic & 12 & Flex & 2 & 60 & 52 & 60 & 55 \\
\hline & 120 & Panic & 10 & Fix & 4 & 69 & 46 & 209 & 142 \\
\hline & 187 & Panic & 12 & Flex & 3 & 123 & 81 & 244 & 180 \\
\hline & $02-002$ & Depression & 6 & Flex & 2 & 34 & 22 & 36 & 25 \\
\hline & $02-003$ & Depression & 6 & Flex & 2 & 33 & 14 & 33 & 21 \\
\hline & $02-004$ & Depression & 4 & Flex & 2 & 40 & 20 & 38 & 22 \\
\hline & $03-001$ & Depression & 4 & Flex & 3 & 38 & 20 & 80 & 39 \\
\hline & 03-002 & Depression & 4 & Flex & 3 & 40 & 14 & 80 & 42 \\
\hline & $03-003$ & Depression & 4 & Flex & 3 & 42 & 22 & 82 & 40 \\
\hline & 03-004 & Depression & 4 & Flex & 3 & 40 & 18 & 80 & 36 \\
\hline & 03-005 & Depression & 6 & Flex & 3 & 42 & 31 & 77 & 57 \\
\hline & $03-006$ & Depression & 6 & Flex & 3 & 37 & 7 & 78 & 33 \\
\hline \multirow[t]{3}{*}{ Quetiapine } & 0006 & Schizophrenia & 6 & Flex & 2 & 55 & 23 & 54 & 28 \\
\hline & 0008 & Schizophrenia & 6 & Flex & 3 & 96 & 41 & 190 & 88 \\
\hline & 0013 & Schizophrenia & 6 & Fix & 7 & 51 & 17 & 310 & 135 \\
\hline \multirow[t]{2}{*}{ Risperidone } & 201 & Schizophrenia & 6 & Flex & 3 & 54 & 16 & 106 & 51 \\
\hline & 204 & Schizophrenia & 8 & Fix & 6 & 88 & 26 & 435 & 228 \\
\hline \multirow[t]{3}{*}{ Sertraline } & 103 & Depression & 6 & Fix & 4 & 91 & 46 & 278 & 145 \\
\hline & 104 & Depression & 8 & Flex & 3 & 150 & 94 & 298 & 184 \\
\hline & 315 & Depression & 8 & Flex & 3 & 86 & 41 & 178 & 96 \\
\hline
\end{tabular}


Table I Continued

\begin{tabular}{|c|c|c|c|c|c|c|c|c|c|}
\hline \multirow[b]{2}{*}{ Psychotropic } & \multirow[b]{2}{*}{ Trial no. } & \multirow[b]{2}{*}{ Disorder } & \multirow[b]{2}{*}{ Length } & \multirow[b]{2}{*}{ Dosing } & \multirow[b]{2}{*}{ Arms } & \multicolumn{2}{|c|}{ Placebo } & \multicolumn{2}{|c|}{ Pscyhotropics } \\
\hline & & & & & & $N$ & Completers & $N$ & Completers \\
\hline & $371 / 372$ & OCD & 12 & Fix & 4 & 84 & 60 & 240 & 176 \\
\hline & 529 & Panic & 12 & Fix & 4 & 44 & 31 & 127 & 82 \\
\hline & 630 & Panic & 10 & Flex & 2 & 88 & 72 & 88 & 71 \\
\hline \multirow[t]{3}{*}{ Venlafaxine ER } & $600 B 2-210$ & GAD & 8 & Fix & 4 & 97 & 78 & 273 & 190 \\
\hline & $600 B 2-214$ & GAD & 8 & Fix & 4 & 104 & 68 & 301 & 188 \\
\hline & 208 & Depression & 12 & Flex & 3 & 91 & 43 & 166 & 88 \\
\hline \multirow[t]{6}{*}{ Venlafaxine } & $600 A-203$ & Depression & 6 & Fix & 4 & 92 & 48 & 231 & 125 \\
\hline & $600 A-206$ & Depression & 4 & Flex & 2 & 47 & 23 & 46 & 36 \\
\hline & $600 A-301$ & Depression & 6 & Flex & 3 & 78 & 47 & 135 & 72 \\
\hline & 600A-302 & Depression & 6 & Flex & 3 & 75 & 44 & 138 & 89 \\
\hline & $600 A-303$ & Depression & 6 & Flex & 3 & 79 & 50 & 142 & 79 \\
\hline & $600 \mathrm{~A}-313$ & Depression & 6 & Fix & 3 & 75 & 54 & 149 & 119 \\
\hline \multirow[t]{3}{*}{ Ziprasidone } & 104 & Schizophrenia & 4 & Fix & 4 & 50 & 27 & 150 & 76 \\
\hline & 106 & Schizophrenia & 4 & Fix & 3 & 48 & 24 & 91 & 52 \\
\hline & 114 & Schizophrenia & 6 & Fix & 3 & 92 & 45 & 210 & 112 \\
\hline
\end{tabular}

Table 2 Completion Rates during Clinical Trials Evaluating Psychotropics for the Treatment of Five Psychiatric Disorders

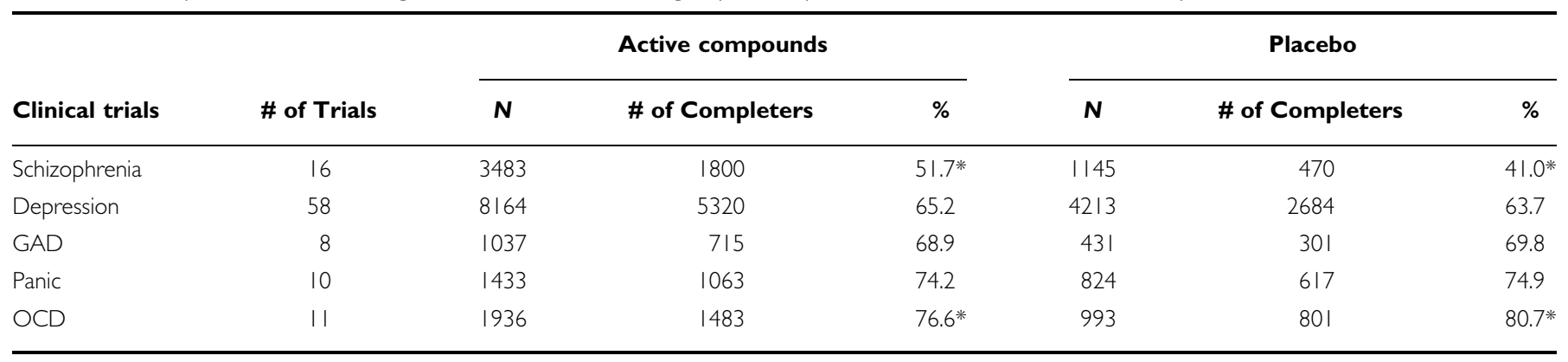

*Significant difference $(p \leqslant 0.05)$ between drug and placebo.

diagnosis categories to determine whether significant differences were present in terms of the number of patients terminating prematurely due to lack of efficacy, terminating due to adverse events, and terminating for other reasons.

Last, we compared the completion rates obtained from this study with rates obtained from a sample found in the literature. We utilized $\chi^{2}$ analysis to compare the differences between the disorders, and also between the active drugs and placebo groups.

\section{RESULTS}

Using $\chi^{2}$ analysis, we found an overall significant difference $\left(\chi^{2}=826.301, \mathrm{df}=4, p \leqslant 0.000\right)$ in completion rates among diagnostic categories, regardless of treatment assignment (psychotropic and placebo). As shown in Table 2, we report the highest completion rates among those patients participating in OCD trials (78\%), followed by panic disorder trials (74.4\%), GAD trials (69.2\%), antidepressant trials $(64.7 \%)$ and antipsychotic trials (49\%). 
Table 3 Comparison of Drug vs Placebo in Terms of Number Terminating Due to Lack of Efficacy, Number Terminating Due to Adverse Events, and Number Terminating for Other Reasons for Each of the Five Psychiatric Diagnoses Examined

\begin{tabular}{|c|c|c|c|c|c|}
\hline Trial & Drug & $\%$ & Placebo & $\%$ & $\mathbf{p}$ \\
\hline \multicolumn{6}{|c|}{ Section A: Number of psychiatric patients terminating early due to lack of efficacy } \\
\hline Depression & $514 / 7602$ & 6.8 & $584 / 4052$ & 14.4 & 0.000 \\
\hline Schizophrenia & $800 / 1683$ & 23.0 & $403 / 1151$ & 35.0 & 0.000 \\
\hline GAD & $21 / 574$ & 3.7 & $|5 / 20|$ & 7.5 & 0.027 \\
\hline OCD & $37 / 1011$ & 3.7 & $42 / 569$ & 7.4 & 0.000 \\
\hline Total & |394/ | 427 & 12.2 & $1091 / 6258$ & 17.4 & 0.000 \\
\hline \multicolumn{6}{|c|}{ Section B: Number of psychiatric patients terminating early due to adverse events } \\
\hline Depression & $895 / 7602$ & 11.8 & $183 / 4052$ & 4.5 & 0.000 \\
\hline Total & | 372/1 3227 & 10.4 & $298 / 6258$ & 4.8 & 0.000 \\
\hline \multicolumn{6}{|c|}{ Section C: Number of psychiatric patients terminating early due to loss of follow-up or other reasons } \\
\hline Depression & $1234 / 7602$ & 16.2 & $711 / 4052$ & 17.5 & NS \\
\hline Schizophrenia & $759 / 3483$ & 21.8 & $220 / 1151$ & 19.1 & NS \\
\hline GAD & $61 / 574$ & 10.6 & $23 / 201$ & 11.4 & NS \\
\hline OCD & $94 / 1011$ & 9.3 & $46 / 569$ & 8.1 & NS \\
\hline Panic disorder & $40 / 557$ & 7.2 & $22 / 285$ & 7.7 & NS \\
\hline
\end{tabular}

*p $>0.05$.

As expected, the differences in completion rates among diagnostic categories remained significant when we examined the rates separately for those patients receiving a psychotropic $\left(\chi^{2}=443.761, \mathrm{df}=4, p \leqslant 0.000\right)$ and those patients assigned to placebo $\left(\chi^{2}=430.683, \mathrm{df}=4, p \leqslant 0.000\right)$.

To evaluate the impact of treatment assignment on completion rates, we analyzed differences in rates between the active compound and placebo groups for the five diagnostic categories using $\chi^{2}$ analysis. During antipsychotic clinical trials, those patients assigned to placebo $(41.0 \%)$ had a significantly lower completion rate compared to those patients assigned to an antipsychotic (51.8\%), $\chi^{2}=38.974$, $\mathrm{df}=1, p \leqslant 0.000$. When we examined OCD trials, we noted that the completion rates were statistically higher among the placebo group $(80.7 \%)$ compared with the psychotropic group $(76.6 \%), \chi^{2}=6.311, \mathrm{df}=1, p=0.0119$.

For the three remaining diagnostic categories - depression (63.7\% placebo, $65.2 \%$ psychotropic), GAD $(69.8 \%$ placebo, $68.9 \%$ psychotropic), and panic disorder $(74.9 \%$ placebo, $74.2 \%$ psychotropic) - the differences in rates between psychotropics and placebo did not reach statistical significance.

Table 3 shows the results of $\chi^{2}$ analyses comparing medication and placebo for each of the five diagnostic categories based on the number of patients terminating due to lack of efficacy (Section A), adverse events (Section B), and loss to follow-up or other reasons (Section $\mathrm{C}$ ). Not surprisingly, for each of the five diagnostic categories, significantly more patients in the placebo group terminated due to lack of efficacy compared to the psychotropic group. Similarly, for every psychiatric diagnosis except schizophrenia, significantly more patients in the psychotropic group terminated due to adverse effects compared with the placebo group. For the schizophrenia sample, an equal percentage $(5.7 \%)$ of patients terminated due to adverse events. No significant differences were found between medication and placebo regarding the number of patients terminating due to loss to follow up and other reasons.

Finally, we used $\chi^{2}$ analysis to examine differences by diagnostic category in completion rates based on number of treatment arms, dosing schedule (fixed vs flexible), and length of trials in weeks. For all three variables we could not establish any pattern in completion rates for all five diagnostic categories. In other words, completion rates did not significantly increase or decrease in increments with additional treatment arms or length of trial, nor did one diagnostic category favor one dosing schedule over another. The only exception occurred in antipsychotic clinical trials. 
The percentage of patients completing 6-week antipsychotic trials $(35.6 \%)$ was significantly lower $\left(\chi^{2}=20.73, \mathrm{df}=1\right.$, $p=0.000)$ than the percentage of patients completing 4 week trials $(49.8 \%)$.

\section{DISCUSSION}

The aim of our study was to assess whether patient characteristics such as psychiatric diagnosis and clinical trial features such as treatment assignment, duration of the clinical trial, dosing schedule, and number of treatment arms may be related to completion rates. Although clinical trial design features such as the duration of the clinical trial, dosing schedule, and number of treatment arms had little relationship to completion rates, both psychiatric diagnosis and treatment assignment (psychotropic $v s$ placebo) showed a significant relationship to clinical trial completion rates.

Overall, patients participating in antipsychotic clinical trials had the lowest completion rate (49.0\%), whereas patients participating in OCD clinical trials had the highest completion rates $(78.0 \%)$. Completion rates varied between 64.7 and $74.4 \%$ for patients with major depression, GAD, and panic disorder during the respective clinical trials.

We found significant differences in overall completion rates between patients treated with a psychotropic and those treated with placebo during antipsychotic and OCD clinical trials. We also found significantly higher completion rates among patients treated with an antipsychotic compared with those treated with placebo. On the other hand, patients assigned to placebo had a higher rate of completion than did patients receiving an OCD agent.

Interestingly, treatment assignment did not play a significant role in completion rates for antidepressant, GAD, or panic disorder clinical trials. In other words, patients in these trials assigned to either a psychotropic or a placebo had similar completion rates.

These results have specific implications for future psychopharmacology clinical trials. First, it is erroneous to assume that completion rates are similar among patients with various psychiatric diagnoses. Second, it is unclear whether completion rates can be significantly changed among psychopharmacology clinical trials as they are currently designed and conducted. For example, it would be impractical and unethical to consider whether completion rates can be significantly increased among patients with schizophrenia in antipsychotic trials where lack of efficacy is the primary reason for discontinuation regardless of treatment assignment. However, with the discovery of a much more effective treatment(s), this pattern may change.

Third, the reasons for early termination rates among psychiatric patients are different among patients assigned to placebo than for patients assigned to psychotropics. The cause of early termination among patients assigned to placebo was much more related to lack of efficacy rather than to adverse events. On the other hand, early termination due to adverse events was higher among patients assigned to psychotropics compared to patients assigned to placebo. Unexpectedly, in these trials rates of early termination from antipsychotic clinical trials for adverse events were similar among patients assigned to the psychotropic compared with those assigned to placebo.

Fourth, the patterns of completion rates are not synonymous with patterns related to primary efficacy measures among these psychopharmacology clinical trials based on our earlier analysis (Khan et al, 2005, see Figure 1). Specifically, the psychotropic-placebo differences were greatest in trials evaluating antipsychotics and OCD agents. The assumption that the larger effect sizes could be due to the higher number of patients completing trials does not bear out when completion rates are evaluated for these two disorders.

In other words, a larger effect size for a psychotropic agent does not imply that completion rates were high among these trials. The antipsychotic and OCD trials with the largest effect sizes had either the lowest or the highest completion rates. Paradoxically, among antidepressant and anxiolytics, the completion rates and effect sizes were intermediary. These data reinforce the concern about generalizability of many psychopharmacology trials (Kemmler et al, 2005) from a single or a small sample of trials.

Last, these data suggest caution in interpreting results from trials such as CATIE because it is evident that completion rates are confounded by several factors. Furthermore, the lack of a placebo control group in such a trial design is problematic. Specifically, the therapeutic index of a majority of psychopharmacology agents is low, meaning the risk-benefit ratio is small, particularly in disorders such as schizophrenia and OCD. Using conventional efficacy measures, the symptom reduction among patients with schizophrenia is approximately $12-15 \%$ from baseline and with placebo the symptom reduction is $1-5 \%$ (Khan et al, 2005). Thus, to detect differences across a group of approved antipsychotics using completion rates as a surrogate efficacy measure would require power in the range of several thousand patients per treatment arm (Leon, 2000).

We were surprised that the completion rates among the clinical trials reported in the FDA SBA reports were significantly higher than the rates in published reports. This was especially true for the OCD clinical trials. Published reports indicated completion rates of $54.5 \%$ (Greist et al, 1995; Koran et al, 2002; Montgomery et al, 1993), whereas the SBA reports indicated completion rates of $78 \%$ during OCD trials. This is a substantial difference in reported completion rates. However, the discrepancies are most likely due to the nature of published reports. The SBA reports include trials with both positive and negative outcomes in trials. Published reports typically include only positive outcomes.

Our findings are directly contrary to what would be expected given the supposition that completion rates should be an indicator of positive trial outcome, in which case the more positively biased published reports would have been expected to show higher rates of completion. Again, this observation undermines the assumption of completion rates as a valid indicator of trial outcome. The only exception was the antipsychotic clinical trials, in which the rates in the SBA reports did not significantly differ from the published reports (Arvanitis and Miller, 1997; Chouinard et al, 1993; Hamilton et al, 1998; Kane et al, 2002; Meltzer et al, 2004; Potkin et al, 2003). 
In conclusion, using FDA SBA reports, we found that study completion rates among patients participating in psychopharmacology clinical trials were significantly associated with the psychiatric diagnosis of the patients. A significant difference was found between completion rates among psychiatric patients assigned to placebo compared with patients assigned to psychotropics in trials evaluating antipsychotic and OCD agents. Furthermore, the reason for terminating early was related to treatment assignment. Significantly more psychiatric patients terminated early when assigned to placebo compared with psychotropics for lack of efficacy, and significantly more psychiatric patients terminated early when assigned to psychotropics compared with placebo for adverse events. These findings suggest that completion rates are not synonymous with efficacy measures, based on earlier analysis of these clinical trials (Khan et al, 2005). Last, these findings suggest caution in using completion rates as a substitute for conventional efficacy measures.

\section{ACKNOWLEDGEMENTS}

Disclosures: The Northwest Clinical Research Center in Bellevue, WA, supported this research from private funds. No support was provided by any pharmaceutical companies or other funding agencies. Dr Khan, principal investigator of more than 200 trials sponsored by more than 40 pharmaceutical companies, has done no consulting or speaking on their behalf. Ms Schwartz and Mr Redding have been employees of the Northwest Clinical Research Center. Dr Kolts has had no support from either pharmaceutical companies or other agencies and is a fulltime employee of Eastern Washington University. Dr Brown is the cofounder and president of Clinical Research Centers International, a company that develops and manages clinical trials sites overseas. These sites carry out research sponsored by drug companies.

\section{REFERENCES}

Andersch S, Rosenberg NK, Kullingsjö H, Ottosson J-O, Bech P, Bruun-Hansen J et al (1991). Efficacy and safety of alprazolam, imipramine and placebo in treating panic disorder: a Scandinavian multicenter study. Acta Psychiatr Scand 365: 18-27.

Anderson IM, Tomenson BM (1995). Treatment discontinuation with selective serotonin reuptake inhibitors compared with tricyclic antidepressants: a meta-analysis. BMJ 310: 1433-1438.

Arvanitis LA, Miller BG, The Seroquel Trial 13 Study Group (1997). Multiple fixed doses of 'Seroquel' (quetiapine) in patients with acute exacerbation of schizophrenia: a comparison with haloperidol and placebo. Biol Psychiatry 42: 233-246.

Baekeland F, Lundwall L (1975). Dropping out of treatment: a critical review. Psychol Bull 82: 738-783.

Ballenger JC, Wheadon DE, Steiner M, Bushnell W, Gergel IP (1998). Double-blind, fixed-dose, placebo-controlled study of paroxetine in the treatment of panic disorder. Am J Psychiatry 155: $36-42$.

Chouinard G, Jones B, Remington G, Bloom D, Addington D, MacEwan GW et al (1993). A Canadian multicenter placebocontrolled study of fixed doses of risperidone and haloperidol in the treatment of chronic schizophrenic patients. J Clin Psychopharmacol 13: 25-40.

Claghorn JL, Kiev A, Rickels K, Smith WT, Dunbar GC (1992). Paroxetine vs placebo: a double-blind comparison in depressed patients. J Clin Psychiatry 53: 434-438.
Cohn JB, Wilcox C (1985). A comparison of fluoxetine, imipramine, and placebo in patients with major depressive disorder. J Clin Psychiatry 46: 26-31.

Dunbar GC, Claghorn JL, Kiev A, Rickels K, Smith WT (1993). A comparison of paroxetine and placebo in depressed outpatients. Acta Psychiatr Scand 87: 302-305.

Dunbar GC, Cohn JB, Fabre LF, Feighner JP, Fieve RR, Mendels J et al (1991). A comparison of paroxetine, imipramine and placebo in depressed out-patients. $\mathrm{Br} J$ Psychiatry 159: 394-398.

Enkelmann R (1991). Alprazolam $v s$ buspirone in the treatment of outpatients with generalized anxiety disorder. Psychopharmacology 105: 428-432.

Fabre LF, Abuzzahab FS, Amin M, Claghorn JL, Mendels J, Petri WM et al (1995). Sertraline safety and efficacy in major depression: a double-blind fixed-dose comparison with placebo. Biol Pyschiatry 38: 592-602.

Feighner JP, Boyer WF (1989). Paroxetine in the treatment of depression: a comparison with imipramine and placebo. Acta Psychiatr Scan 350: 125-129.

Fontaine R, Ontiveros A, Elie R, Kensler TT, Roberts DL, Kaplita S et al (1994). A double-blind comparison of nefazodone, imipramine, and placebo in major depression. J Clin Psychiatry 55: 234-241.

Gelenberg AJ, Lydiard RB, Rudolph RL, Aguiar L, Haskins JT, Salinas E (2000). Efficacy of venlafaxine extended-release capsules in nondepressed outpatients with generalized anxiety disorder. JAMA 283: 3082-3088.

Greist J, Chouinard G, DuBoff E, Halaris A, Kim SW, Koran L et al (1995). Double-blind parallel comparison of three dosages of sertraline and placebo in outpatients with obsessive-compulsive disorder. Arch Gen Psychiatry 52: 289-295.

Hamilton SH, Revicki DA, Genduso LA, Beasley Jr CM (1998). Olanzapine $v s$ placebo and haloperidol: quality of life and efficacy results of the North American double-blind trial. Neuropsychopharmacology 18: 41-49.

Kane JM, Carson WH, Saha AR, McQuade RD, Ingenito GG, Zimbroff DL et al (2002). Efficacy and safety of aripiprazole and haloperidol vs placebo in patients with schizophrenia and schizoaffective disorder. J Clin Psychiatry 63: 763-771.

Kemmler G, Hummer M, Widschwendter C, Fleischhacker WW (2005). Dropout rates in placebo-controlled and active-control clinical trials of antipsychotic drug. Arch Gen Psychiatry 62: 1305-1312.

Khan A, Detke M, Khan S, Mallenkrodt C (2003a). Placebo response and antidepressant clinical trial outcomes. J Nerv Mental Dis 19: 211-218.

Khan A, Khan SR, Walens G, Kolts R, Giller EL (2003b). Frequency of positive studies among fixed and flexible dose antidepressant clinical trials: an analysis of the Food and Drug Administration Summary Basis of Approval reports. Neuropsychopharmacology 28: $552-557$.

Khan A, Kolts RL, Rapaport MH, Krishnan KRR, Brodhead AE, Brown WA (2005). Magnitude of placebo response and drugplacebo differences across psychiatric disorders. Psychol Med 35: 743-749.

Khan A, Kolts RL, Thase ME, Krishnan KRR, Brown W (2004). Research design features and patient characteristics associated with the outcome of antidepressant clinical trials. $A m \mathrm{~J}$ Psychiatry 161: 2045-2049.

Khan A, Schwartz K (2005). Design features that affect psychopharmacology trials. Lett Drug Des Discovery 2: 546-550.

Kiev A (1992). A double-blind, placebo-controlled study of paroxetine in depressed outpatients. J Clin Psychiatry 53(Suppl 2): 27-29.

Koran LM, Hackett E, Rubin A, Wolkow R, Robinson D (2002). Efficacy of sertraline in the long-term treatment of obsessivecompulsive disorder. Am J Psychiatry 159: 88-95. 
Labelle A, Boulay LJ, Lapierre YD (1999). Retention rates in placebo- and nonplacebo- controlled clinical trials of schizophrenia. Can J Psychiaty 44: 887-892.

Lecrubier Y, Bakker A, Dunbar G, Judge R, The Collaborative Paroxetine Panic Study Investigators (1997). A comparison of paroxetine, clomipramine and placebo in the treatment of panic disorder. Acta Pscyhiatr Scand 95: 145-152.

Lecrubier Y, Judge R, the Collaborative Paroxetine Panic Study Investigators (1997). Long-term evaluation of paroxetine, clomipramine and placebo in panic disorder. Acta Psychiatr Scand 95: 153-160.

Leon AC (2000). Placebo protects subjects from nonresponse: a paradox of power. Arch Gen Psychiatry 57: 329-330.

Lieberman JA, Stroup TS, McEvoy JP, Swartz MS, Rosenheck RA, Perkins DO et al (2005). Effectiveness of antipsychotic drugs in patients with chronic schizophrenia. N Eng J Med 353: 1209-1221.

Liebowitz MR, Stein MB, Tancer M, Carpenter D, Oakes R, Pitts CD (2002). A randomized, double-blind, fixed-dose comparison of paroxetine and placebo in the treatment of generalized social anxiety disorder. J Clin Psychiatry 63: 66-74.

Lineberry CG, Johnston JA, Raymond RN, Samara B, Feighner JP, Harto NE et al (1990). A fixed-dose $(300 \mathrm{mg})$ efficacy study of bupropion and placebo in depressed outpatients. J Clin Psychiatry 51: 194-199.

Londborg PD, Wolkow R, Smith WT, DuBoff E, England D, Ferguson J et al (1998). Sertraline in the treatment of panic disorder. Br J Psychiatry 173: 54-60.

Lydiard RB, Stahl SM, Hertzman M, Harrison WM (1997). A double-blind, placebo-controlled study comparing the effects of sertraline $v s$ amitriptyline in the treatment of major depression. J Clin Psychiatry 58: 484-491.

Meltzer HY, Arvanitis L, Bauer D, Rein W, Meta-trial study group (2004). Placebo-controlled evaluation of four novel compounds for the treatment of schizophrenia and schizoaffective disorder. Am J Psychiatry 161: 975-984.

Mendels J, Reimherr F, Marcus RN, Roberts DL, Francis RJ, Anton SF (1995). A double-blind, placebo-controlled trial of two dose ranges of nefazodone in the treatment of depressed outpatients. J Clin Psychiatry 56(Suppl 6): 30-36.

Montgomery SA, McIntyre A, Osterheider M, Sarteschi P, Zitterl W, Zohar J, et al, The Lilly European OCD Study Group (1993). A double-blind, placebo-controlled study of fluoxetine in patients with DSM-III-R obsessive-compulsive disorder. Euro Neuropsychopharmacol 3: 143-152.

Mullins CD, Shaya FT, Meng F, Wang J, Harrison D (2005). Persistence, switching, and discontinuation rates among patients receiving sertraline, paroxetine, and citalopram. Pharmacotherapy 25: 660-667.

Pelagotti F, Santarlasci B, Vacca F, Trippoli S, Messori A (2004). Dropout rates with olanzapine or risperidone: a multi-centre observational study. Eur J Clin Pharmacol 59: 905-909.

Pollack MH, Otto MW, Worthington JJ, Manfro GG, Wolkow R (1998). Sertraline in the treatment of panic disorder. Arch Gen Psychiatry 55: 1010-1016.

Potkin SG, Saha AR, Kujawa MJ, Carson WH, Ali M, Stock E et al (2003). Aripiprazole, and antipsychotic with a novel mechanism of action, and risperidone vs placebo in patients with schizophrenia and schizoaffective disorder. Arch Gen Psychiatry 60: 681-690.

Rapaport MH, Wolkow R, Rubin A, Hackett E, Pollack M, Ota KY (2001). Sertraline treatment of panic disorder: results of a longterm study. Acta Psychiatr Scand 104: 289-298.

Reimherr FW, Chouinard G, Cohn CK, Cole JO, Itil TM, LaPierre YD et al (1990). Antidepressant efficacy of sertraline: a double blind, placebo-and amitriptyline-controlled, multicenter comparison study in outpatients with major depression. J Clin Pyschiatry 51(Suppl 12B): 18-27.

Rickels K, Amsterdam J, Clary C, Gox I, Schweizer E, Weise C (1992). The efficacy and safety of paroxetine compared with placebo in outpatients with major depression. J Clin Psychiatry 53(Suppl 2): 30-32.

Rickels K, Pollack MH, Sheehan DV, Haskins JT (2000). Efficacy of extended-release venlafaxine in nondepressed outpatients with generalized anxiety disorder. Am J Psychiatry 157: 968-974.

Shrivastava RK, Shrivastava SHP, Overweg N, Blumhardt CL (1992). A double-blind comparison of paroxetine, imipramine, and placebo in major depression. J Clin Psychiatry 53(Suppl 2): $48-51$.

Smith WT, Glaudin V (1992). A placebo-controlled trial of paroxetine in the treatment of major depression. $J$ Clin Psychiatry 53(Suppl 2): 36-39.

Stein MB, Liebowitz MR, Lydiard RB, Pitts CD, Bushnell W, Gergel I (1998). Paroxetine treatment of generalized social phobia (social anxiety disorder). JAMA 280: 708-713. 